\title{
A disseminação da pesquisa ambiental: um desafio para a comunicação científica ${ }^{1}$
}

\author{
Renata C. SARTORI ${ }^{2}$ \\ Maria Conceição de ALMEIDA ${ }^{3}$ \\ Arlete A. MONTEIRO ${ }^{4}$ \\ Universidade Federal do Rio Grande do Norte, Natal, RN \\ Pontifícia Universidade Católica, São Paulo, SP
}

\section{RESUMO}

Este artigo aborda a relação entre a comunicação científica e a pesquisa ambiental. O conhecimento científico fragmentado é incapaz de compreender a dinâmica da complexa rede que envolve a temática ambiental. Com isso surge um desafio no campo de ensino e nas práticas de pesquisa, cujos resultados são disseminados pelos periódicos científicos que podem ou não legitimar novas formas de conhecimento. Neste sentido, apresentamos algumas reflexões sobre as funções da comunicação científica, da responsabilidade do pesquisador, bem como da necessidade de uma reformulação das políticas dos periódicos científicos, implicando maior visibilidade para as pesquisas, que apreendam a complexidade ambiental.

Palavras-chave: comunicação e meio ambiente; periódico científico; complexidade ambiental.

\begin{abstract}
This article discusses the relationship between environmental research and scientific communication. The scientific knowledge is fragmented unable to understand the dynamics of complex network that involves environmental issues. With this comes a challenge in the field of teaching and practice of research, whose results are disseminated by journals that may or may not legitimize new forms of knowledge. Thus, we present some reflections on the functions of scientific communication, the responsibility of the researcher as well as the need for an overhaul of the policies of scientific journals, resulting in greater visibility for research, which seize the environmental complexity.
\end{abstract}

Keywords: Environmental communication, journal, environmental complexity.

\footnotetext{
1 Trabalho apresentado à segunda edição da Revista Ação Midiática - Estudos em Comunicação, Sociedade e Cultura, publicação ligada ao Programa de Pós-Graduação em Comunicação e Sociedade, da Universidade Federal do Paraná.

2 Jornalista. Mestre em Ecologia Aplicada-CENA/ESALQ/USP-Piracicaba-SP. Doutoranda em Ciências Sociais/UFRN-Natal-RN. Bolsista CAPES-PDEE. Faculdade de Ciências Sociais da Universidade de SalamancaEspanha. Pesquisadora do Grupo de Estudos da Complexidade (GRECOM/Natal-RN). Email: resartori@ibest.com.br
} 
3 Antropóloga. Professora Titular da Universidade Federal do Rio Grande do Norte/Natal-RN. Coordenadora do Grupo de Estudos da Complexidade - GRECOM/Natal-RN.

${ }^{4}$ Professora Titular da Pontifícia Universidade Católica de São Paulo. Professora visitante da Universidad Pablo de Olavide, Sevilha, Espanha. Pesquisadora e membro da diretoria do CERU (Centro de Estudos Rurais e Urbanos), USP-São Paulo. 
O avanço das pesquisas científicas depende do intercâmbio da troca de observações e experiências entre cada membro da comunidade científica. A necessidade de trocar dados, desenvolver teorias e experiência e, simultaneamente, modificar ideias, faz com que os cientistas se envolvam com comunicação, tais como os periódicos científicos, considerados uma forma de comunicação destinada à comunidade científica.

Os periódicos foram criados em 1665 e transformaram-se de um veículo com finalidade de publicar notícias científicas, em um veículo de divulgação do conhecimento que se originou das atividades de pesquisa (MIRANDA, 1996, p.380).

Segundo Meadows (1999, p.7), os periódicos científicos surgiram na metade do século XVII por várias razões, tais como: a expectativa de seus editores em relação ao lucro e a crença de que para fazer novos descobrimentos era preciso que houvesse um debate coletivo. Mas o motivo principal foi a necessidade de comunicação, do modo mais eficiente possível, entre uma clientela crescente interessada em novas realizações científicas.

A Associação Brasileira de Normas Técnicas (ABNT), (1978, p.9-12) define periódicos como:

Publicações editadas em fascículos, números ou pares, a intervalos prefixados, por tempo indeterminado, com a colaboração de várias pessoas, sob a direção de uma ou de várias, em conjunto ou sucessivamente, tratando assuntos diversos, segundo plano definido.

Segundo Herschman (1970, p.37-42), o periódico científico possui três funções básicas:

É um registro oficial e público da ciência, consolidando o reconhecimento de prioridades de descobertas e/ou idéias (função memória); constituí um meio para difundir tanto a informação primária como a secundária (função disseminação) e é uma Instituição social que confere prestígio e recompensa aos autores, aos membros do conselho da redação e aos editores (função social).

Gomes (1990, p.98) classifica as revistas especializadas em ciência e tecnologia em dois tipos: revistas de disseminação e revistas de divulgação científica. Ambas têm como objetivo primordial a difusão da ciência; as revistas de disseminação veiculam o 
conhecimento e são produzidas por pesquisadores, dirigidas aos pares e, por isso mesmo, publicam textos altamente especializados que, provavelmente, só serão compreendidos por profissionais da área do conhecimento do assunto abordado.

Os periódicos científicos difundem a ciência com o propósito de mostrar ao público a validade das pesquisas relatadas e gerar mais conhecimento; são produzidos por cientistas visando atingir os especialistas e a linguagem é acessível apenas entre eles. Neles estão as tendências seguidas pelas pesquisas em várias nações e as prioridades para as várias áreas de pesquisa científica, além de serem veículos fundamentais para o registro do conhecimento e serem capazes de atingir grande número de leitores por seu caráter permanente.

A pesquisa científica e a divulgação de seus resultados são atividades inseparáveis: divulgar resultados não é um complemento, mas uma das etapas essenciais do trabalho de investigação, que só se complementa quando o trabalho for comunicado.

Para Le Coadic (1996, p.27), sem informação, a ciência não pode se desenvolver e viver: "Sem informação a pesquisa seria inútil e não existiria o conhecimento [...] a informação só interessa se circula, e, sobretudo, se circula livremente". Entretanto, para a circulação da informação ocorrer livremente há em seu caminho muitos percalços, principalmente encontrados nas universidades públicas e que são criticados por diversos autores.

Targino (2001, p.33) mostra que os pesquisadores acadêmicos confundem divulgação de resultados com a indústria da pesquisa e papers. Portanto, o objetivo máximo da investigação científica — busca de respostas para um problema determinado - acaba sendo substituído por uma produção meramente quantitativa de artigos e papers. A intenção primordial passa a ser garantir pontos para ascensão profissional, conceitos mais elevados para os programas de pós-graduação e concessão de benefícios. Ao contrário, a autora defende que os cientistas devem "visualizar a divulgação de resultados como expressão de sua função social como pesquisador".

Sabe-se que não há ciência sem comunicação e não há comunicação sem informação. A comunicação científica é indispensável à atividade científica, mas a produção da ciência não se dá alheia ao contexto social em que ela se insere, devendo 
ultrapassar as fronteiras da comunidade de usuários mais imediatos, sob o risco de se tornar estéril e inútil.

Conforme relata Lima (http://www.revistapesquisafapesp.br, 20 out., 2002), os meios de ligação entre a ciência profissional e a comunidade em geral têm sido motivo de preocupação sistemática por parte dos cientistas e dos governantes. Esse fato foi atestado em 1831 com a criação da British Association for the Development of Science.

Anteriormente, no século XVII, Francis Bacon já insistia na questão da responsabilidade da ciência para com a humanidade. Um esforço de divulgação dos avanços da ciência e da tecnologia, para ele, era não só uma necessidade como um dever social. Além disso, devemos destacar o desenvolvimento do jornalismo científico, crescente em nossos dias, tanto em jornais diários como em revistas científicas.

A partir deste cenário também surge outra questão contemporânea - a complexidade dos problemas ambientais que abrange o contexto social, cultural, econômico, político entre outros, tornando-se fundamental que esses contextos sejam inseridos na pesquisa acadêmica, resultando numa produção científica que venha a contribuir para a reflexão e solução dos problemas ambientais.

Nesse sentido, Ribeiro (2003, p.A3) também destaca a responsabilidade social do pesquisador aliada à qualidade de pesquisa:

Não podemos pesquisar sem levar em conta nossa responsabilidade social. Numa sociedade mais justa, sem miséria ou devastação ambiental, poderíamos pensar só por pensar. Aqui não. É como cientistas que melhor podemos contribuir para o avanço do país. Não podemos abrir mão da qualidade de pesquisa.

Chauí (2001, p.153) formula um conceito geral de excelência na pesquisa e define pesquisa excelente como "aquela que, tratando de algo particular, o faz de tal maneira que seu alcance, seu sentido e seus efeitos tendam a ser universalizáveis, e que poderá vir a ser publicada e conhecida internacionalmente”. Ressaltamos, porém, que há áreas de estudos, principalmente nas ciências humanas, em que são realizadas pesquisas com particularidades locais e regionais, sem deixar de ter caráter de excelência.

A problemática ambiental dotada de complexidade vem propiciando uma crítica ao pensamento científico herdado, no qual a fragmentação do conhecimento mecanicista impede a compreensão desta complexidade, o que vem a requerer uma nova capacidade 
perceptiva da própria ciência. Este é um dos maiores desafios que esta problemática coloca: a reformulação do conhecimento.

Para a concretização desta reformulação torna-se indispensável desenvolver um conhecimento científico baseado em novos paradigmas, ou seja, uma nova forma de ver e pensar a realidade para posterior agir, conforme explica Capra (1982), nos princípios básicos ecológicos; Leff (2002), na sua teoria do saber ambiental; Morin (2002) pelo paradigma da complexidade; Santos (2001) por intermédio do paradigma emergente, entre outros. Também é imprescindível a disseminação de pesquisas baseadas nesses conhecimentos, o que tem gerado outro grande desafio para os cientistas, resultando em constantes dificuldades para publicação das suas pesquisas, uma vez que a maioria dos periódicos científicos ainda apresenta em seu escopo, temáticas "engessadas", além do que, a definição de formas de valorização dos resultados produzidos pela pesquisa de caráter interdisciplinar "não encontra unanimidade entre os pesquisadores" (ZANONI, 2000, p.219).

Como exemplo, citamos um estudo sobre artigos publicados no período de 1998 a 2002 em um periódico científico consolidado, fundado em 1944, considerado o principal periódico de uma universidade pública brasileira e importante veículo de disseminação do conhecimento científico agrário. As finalidades da pesquisa foram verificar as características do periódico (temáticas, periodicidade, tiragem, conceito, bases indexadoras etc.), bem como verificar, quais os enfoques adotados pelas pesquisas publicadas em forma de artigos, tendo como referencial teórico o pensamento da complexidade de Edgar Morin. Para tanto, foram direcionadas para análise dos artigos as inter-relações que implicam a integração de processos naturais e sociais, atentando para que estes últimos não fossem absorvidos por enfoques ecologistas ou visões biologistas. Também se considerou na rede da complexidade ambiental, os artigos sobre as comunidades tradicionais (por exemplo: as pesquisas etnobotânicas), além do segmento acadêmico (SARTORI, 2005).

O estudo verificou que o periódico de circulação trimestral, visa segundo a seção Instruções aos Autores, publicar artigos originais elaborados por especialistas nacionais e estrangeiros que contribuam para o desenvolvimento científico das Ciências Agrárias. Apesar das temáticas serem diversificadas, tais como: Produção Vegetal, Produção Animal, Engenharia Rural, Economia e Sociologia, Tecnologia Agroindustrial, Ciências Florestais, Ciências Ambientais e do Solo e Ciências Básicas Aplicadas à Agricultura, 
nas publicações de 2001 e 2002, constatou-se maior número de artigos destinados às seções de Solo e Fitotecnia, e um número insignificante de artigos sobre Economia, Sociologia e Ciências Ambientais. Ressalte-se que até o ano de 1999 os artigos não eram categorizados, ou seja, as seções temáticas surgiram em 2000.

Dos 116 artigos analisados apenas 1 (um), publicado em 1999, apresentou uma abordagem voltada para complexidade ambiental com nove páginas, ou seja, levou-se em consideração a inter-relação entre saberes e práticas, envolvendo pesquisadores do departamento de Genética de uma universidade com agricultores, os quais herdaram uma gama de conhecimentos transmitidos oralmente sobre a agricultura praticada por povos indígenas, tendo a mandioca como principal cultivo. Os autores consideraram os aspectos sociais, ecológicos, as etnovariedades da mandioca, entre outros.

Os 115 artigos restantes se limitaram a levantar dados específicos, conforme já mencionado. Embora, a maioria dos problemas ambientais tenha suas raízes em fatores sociais, econômicos e culturais, tornou-se visível que estes artigos minimizaram ou reduziram a especificidade destes fatores em suas abordagens, explicitando indícios de que a conexão entre estes fatores com o ambiental, limitou-se ao propósito de internalizar normas tecnológicas e ecológicas para a restauração do ambiente (por exemplo: as pesquisas de experimentos, ou seja, aquelas que se valem de um experimento em laboratório, em campo de produção ou campo experimental), deixando à margem a análise do conflito social da realidade brasileira e até mesmo o terreno estratégico político que atravessa o campo ambiental. Também estavam ausentes nos artigos as numerosas inter-relações, como exemplo, as existentes entre o uso da terra, a agricultura, a pecuária e a sociedade.

Uma percepção clara dos processos interconectados que ocorrem no ambiente não pode ser alcançada sem a descrição e avaliação das causas sociais de mudanças no uso da terra, da água etc., e seus efeitos que geram alterações nos ecossistemas afetando os seres vivos, a fauna, a flora.

De acordo com Acot (1990, p.41), surgiram em 1890, nos Estados Unidos, as publicações de caráter ecológico, sendo a obra do botânico oficial do Estado de Minnesota, Conway McMillan uma das primeiras publicações americanas de natureza ecológica, datando de 1897. 
Aqui abrimos um parênteses para um exemplo de periódico fundado em 1940, pelo educador americano Fritz Kunz, intitulado Main Currents in Modern Thought; nessa época seus artigos tratavam da relação homem e natureza, sujeito e objeto, interioridade e exterioridade; em suma, já havia uma preocupação, como pode ser comprovado em seus artigos, da relação do homem com a natureza.

O periódico provocou um impacto na cultura americana, sem alarde, por mais de trinta anos. Seu objetivo era promover a livre associação daqueles que trabalham conjuntamente para integrar a soma do conhecimento através da totalidade das coisas: natureza, homem e sociedade, considerando o universo uno, verossímil, inteligível, harmonioso (WEBER,1986, p.11).

O Main Currents in Modern Thought circulou até 1975, conquistando colaboradores que já nesse período (1940-1975) trabalhavam nas fronteiras de seus campos de conhecimentos: Heisenberg, Eugene Wigner, Von Bertalanffy, Jean Charon entre outros. "Em 1972 o periódico publicou um artigo de um jovem físico desconhecido, Fritjof Capra, extraído de um livro publicado, posteriormente, "The tao of physics" (WEBER, 1986, p.11).

Em 1970 foi lançada a revista Ecologist na Grã-Bretanha, vindo a ser "um poderoso meio de contribuição e fermentação de idéias na área ambiental” (DIAS, 2003, p.34).

Segundo Seifert (1998, p.113), desde os anos 1970 a pesquisa ambiental vem se ampliando e conseguiu caracterizar, em muitos campos, os sintomas de degradação e desenvolver indicadores de modificações ambientais que alimentaram bases de dados associadas a programas de modelagem ambiental. Para o autor, pode-se obter previsões confiáveis sobre as tendências relativas ao ambiente e implementar medidas preventivas, afirmando que "em muitas áreas da pesquisa ambiental, o trabalho é de caráter interdisciplinar e de natureza eminentemente preventiva".

A importância da comunicação científica relacionada às questões ambientais também foi destacada em 1992 com o lançamento da Agenda 21, cujo capítulo 35 intitulado A Ciência para o Desenvolvimento Sustentável, aborda o papel e a utilização das ciências no apoio ao manejo cauteloso do meio ambiente visando à sobrevivência e ao desenvolvimento da humanidade: "Um dos papéis da ciência é oferecer informação para permitir uma melhor formulação e seleção das políticas do meio ambiente e 
desenvolvimento no processo de tomada de decisões" (http://www.mma.gov.br/port/se/agen21/cap35.html, 28 fev. 2004).

Neste sentido, Leite (2004, p.A3) ressalta o papel da universidade como uma instituição que tem como objetivos fundamentais a geração e a difusão do conhecimento: "A primeira dessas tarefas é realizada por meio da pesquisa, e a segunda pelo ensino e diversas formas de transferências de conhecimento para outros segmentos da sociedade”. Conforme Leite, POBLACÍON (1994, p.127-129) afirma que a projeção da universidade, como centro gerador de novos conhecimentos, "incontestavelmente se efetiva através da pesquisa".

Pelo fato dos problemas ambientais colocarem em xeque o modo de produção de uma sociedade, o modo e a qualidade de vida dos seres, entre outros, o enfoque da pesquisa ambiental deve e pode redirecionar em profundidade, o atual paradigma relacionado ao conhecimento mecanicista e estabelecer novos métodos para a compreensão da complexidade da temática ambiental, fazendo com que sejam fixadas as bases que deverão provocar mudanças e transformações nas pesquisas científicas, a partir de conhecimentos articulados, contextualizados, contribuindo para uma maior troca de saberes e visibilidade.

Diante deste cenário, se torna fundamental repensar o papel que está sendo desenvolvido pelos periódicos científicos, suas políticas de submissão de artigos, suas atuais linhas temáticas, suas características estruturais, administrativas, entre outras; bem como o papel dos pesquisadores, da sua função social e para além da comunidade científica, deles reconhecerem a necessidade de que suas informações científicas sejam também repassadas à população, assumindo objetivos comuns como cidadãos planetários.

\section{Referências}

ACOT, P. História da ecologia. 2.ed. Rio de Janeiro: Campus, 1990. 212p. DE DOCUMENTAÇÃO. Normas ABNT sobre documentação: NB 62. Rio de Janeiro: ABNT, 1978. v.1. p.9-12. 
CAPRA, F. O ponto de mutação: a ciência, a sociedade e a cultura emergente. São Paulo: Cultrix, 1982. 447p.

CHAUÍ, M. Escritos sobre a universidade. São Paulo: Vozes, 2001. 205p.

DIAS, G.F. Educação ambiental: princípios e práticas. 8.ed., São Paulo: Gaia， 2003. 551p.

GARVEY, W.D. Communication: the essence of science. Oxford: Pergamon, 1979. 332p.

GOMES, I.M.A. Revistas de divulgação científica: um panorama brasileiro. Revista Ciência \& Ambiente. v.1, p.95-107, jun.1990.

HERSCHMAN, A. The primary journal: past, present and future. Journal of Chemical Documentation, v.10, n.1, p.37-42, 1970.

LE COADIC, Y. A ciência da informação. Brasília: Briquet de Lemos/Livros， 1996. 199p.

LEFF, E. Saber ambiental: sustentabilidade, racionalidade, complexidade e poder. 2.ed. Rio de Janeiro: Vozes, 2002b. 343p.

LEITE, R.C.C. A reforma universitária e o corporativismo. Folha de S.Paulo.

Tendências/Debates, São Paulo, 07 abr. 2004. p.A3.

LIMA, J.C.V. Divulgação científica e sociedade. [http://www.revistapesquisafapesp.br]. Acesso em: 20 out. 2002.

MEADOWS, A.J. A comunicação científica. Brasília: Briquet de Lemos/Livros, 1999. 268p.

MINISTÉRIO DO MEIO AMBIENTE: AGENDA 21

[http://www.mma.gov.br/port/se/agen21/cap35.html]. Acesso em: 28 fev. 2004.

MIRANDA, D.B. O periódico científico como veículo de comunicação: uma revisão de literatura. Revista Ciência da Informação, v.25, n.3, p.375-380, 1996.

MORIN, E. A religação dos saberes: o desafio do século XXI. 2.ed. Rio de Janeiro: Bertrand Brasil, 2002b. 583p.

POBLACIÓN, D.A. Globalização do conhecimento e difusão da produção científica gerada na universidade brasileira. Revista Brasileira de Comunicação, v. 17, n.1, p.121-138, jan./jun. 1994. 
RIBEIRO, R.J. Por uma SBPC com maior atuação social. Folha de S.Paulo.

Tendências/Debates, São Paulo, 13 mai. 2003. p.A3.

SANTOS, B.S. A crítica da razão indolente: contra o desperdício da experiência. 3.ed. São Paulo: Cortez, 2001a. 415p.

SARTORI, R.C. O pensamento ambiental sistêmico: uma análise da comunicação científica da ESALQ/USP. Piracicaba. 2005. 109p. Tese (Mestrado) - Escola Superior de Agricultura Luiz de Queiroz. Universidade de São Paulo.

SEIFFERT, N.F. O desafio da pesquisa ambiental. Cadernos Ciência \& Tecnologia. v.15, n.3, p.103-122, set./dez. 1998.

TARGINO, M.G. Divulgação de resultado como expressão da função social do pesquisador. Revista Brasileira de Ciências da Comunicação, v.29, n.1, p.11-35, jan./jun. 2001.

ZANONI, M. Práticas interdisciplinares em grupos consolidados. In: PHILLIP JÚNIOR, A.; TUCCI, C.E.M.; HOGAN, D.J.; NAVEGANTES, R. (Ed.) Interdisciplinaridade em ciências ambientais. São Paulo: Signus, 2000. p.111-130.

WEBER, R. Diálogos com cientistas e sábios: a busca da unidade. São Paulo: Cultrix, 1986. $302 p$. 